\title{
Avaliação de programa de atenção à saúde: incentivo à oferta de atenção ambulatorial e a experiência da descentralização no Brasil
}

\author{
Evaluation of health care program: incentives \\ for ambulatory care supply and the decentralization \\ experience in Brazil
}

Nilson do Rosário Costa 1

Luiz Felipe Pinto 1,2

\footnotetext{
1 Departamento de Ciências Sociais da Escola Nacional de Saúde Pública, Fiocruz. Av. Leopoldo Bulhões 1480, 9o andar, 21041-210 Manguinhos, Rio de Janeiro RJ. nilson@ensp.fiocruz.br 2 Faculdade de Medicina de Teresópolis (FESO).
}

Abstract The article analyses the results of the research Cost and Evaluation of the Impact of the Implantation of the Basic Care Incentive (Piso de Atenção Básica), which evaluated the decentralization of health services through incentives for primary care services supply. From a retrospective longitudinal study, the changes in the structure of the federal financial incentives for States and Municipalities are analyzed. The article also discusses the impact of the basic care oriented policy on the supply of the ambulatorial care and in the health care labor force at municipal level. The paper shows a meaning increase of the ambulatorial and primary care supply in the public sector in Brazil in the nineties. The small cities has been soundly favored with the new financial incentives from the public policy.

Key words Ambulatory care, Decentralization, Primary care financing, Program evaluation; Health care supply
Resumo O artigo discute alguns dos resultados da pesquisa Custo e Avaliação do Impacto da Implantação da Parte Fixa do Piso de Atenção Básica (PAB), que avaliou a descentralização dos serviços de saúde pelo Programa $P A B$. A partir de um estudo longitudinal retrospectivo, são analisadas as mudanças na estrutura das transferências federais para estados e municípios, contemplando a organização da atenção ambulatorial e básica e os recursos humanos em saúde. Por força de incentivos à oferta, torna-se evidente o crescimento da atenção ambulatorial e básica do Sistema Único de Saúde nos pequenos municípios brasileiros na década de 1990.

Palavras-chave Atenção ambulatorial, Avaliação em saúde, Descentralização, Financiamento à atenção primária, Avaliação de programa 


\section{Introdução}

Este texto baseia-se nos resultados finais da pesquisa Custo e Avaliação do Impacto da Implantação da Parte Fixa do Piso de Atenção Básica - PAB (ENSP/REFORSUS, 2002), que avaliou a descentralização dos serviços de saúde sob a ótica do incentivo financeiro do PAB para um grupo de procedimentos ambulatoriais.

A descentralização da provisão da atenção saúde foi considerada, ao longo da década de 1980 , o caminho mais adequado para aumento da responsabilização dos gestores e garantia de efetividade da assistência. Em fins dessa década, algumas hipóteses foram formuladas sobre os incentivos que os gestores locais teriam para implementar objetivos de saúde e melhorar o desempenho dos sistemas locais (Bossert, 1998).

Para muitos dos programas de saúde, implementados de modo descentralizado, a dependência para o bom resultado das decisões do gestor local tornou-se uma variável decisiva. Esse é o caso dos programas de ampliação de cobertura na atenção básica desenvolvidos no Brasil desde meados da década de 1990, sendo o exemplo mais expressivo, o Programa de Saúde da Família. A qualidade do desempenho do sistema de saúde brasileiro na atenção básica está diretamente associada ao processo decisório municipal e estadual.

O Piso Assistencial Básico (PAB) criado pela portaria GM/MS no 1.882, de 18/12/1997 e em vigor desde fevereiro de 1998, constituiu uma medida decisiva na perspectiva da descentralização financeira do sistema de saúde no Brasil, incentivando os municípios a assumirem, progressivamente, a gestão da rede básica de serviços de saúde.

Esse incentivo federal visou assegurar aos municípios um valor per capita de $\mathrm{R} \$ 10,00$, repassado pelo governo federal, destinado exclusivamente ao custeio de um elenco específico de procedimentos (grupos de 1 a 5 do SIA-SUS). A implementação do PAB trouxe como principal novidade a chamada transferência regular e automática, onde o repasse federal é feito diretamente aos municípios. A condição de habilitação ao PAB é definida pela NOB/96 e obriga a criação de um Fundo Municipal de Saúde e um Conselho Municipal de Saúde, dando maior autonomia e responsabilidade ao gestor municipal.

O novo mecanismo dissociou a produção do faturamento, característica central do sistema anterior. Isto é, de acordo com o sistema de pagamento por serviços previamente prestados, os municípios mais pobres e, portanto, sem uma infra-estrutura adequada de unidades e de estabelecimentos de saúde, acabavam prejudicados. Comparados aos municípios mais desenvolvidos, recebiam do SUS valores menores, porém coerentes, por um lado, com a precariedade da rede de saúde existente no local, e por outro, com a quantidade de procedimentos e atendimentos realizados. Quanto maior o número de hospitais, ambulatórios e postos de saúde, maior era a possibilidade de o município receber aportes financeiros do SUS. O antigo sistema, por meio do faturamento em cima do número de doentes e de procedimentos realizados, perpetuava um modelo de atenção distorcido, com pouca ênfase na adoção de medidas preventivas e de promoção à saúde.

Um estudo exploratório realizado pelo Ministério da Saúde em 1997, baseado em dados do SIA/SUS para o ano de 1996 (Ministério da Saúde, Relatório do MS-GTT/PAB, 1998), revelou que aproximadamente $70 \%$ dos municípios brasileiros (mais ou menos 3.860 municípios) receberam naquele ano menos de $\mathrm{R} \$ 10,00$ per capita. Esse dado permite formular a hipótese de que os recursos do $\mathrm{PAB}$ - chegando diretamente aos municípios mais carentes, com maior déficit de atendimento e com uma rede de serviços de menor complexidade, podem provocar um forte impacto na qualidade da assistência básica, promovendo, indiretamente, uma mudança gradual no atual modelo de saúde.

Em síntese, o PAB trouxe inovações importantes que devem ser avaliadas (Quadro 1)

A possibilidade de investigar o impacto do PAB permite, na verdade, mover o foco do debate sobre a situação do sistema de saúde brasileiro de uma visão pessimista da experiência de descentralização e da perspectiva excessivamente otimista em relação às suas virtudes intrínsecas (Barros Silva \& Costa, 2000).

As análises pessimistas assinalaram um conjunto de riscos associado aos processos de descentralização, como a baixa capacidade de gestão dos municípios na área de saúde; o uso das transferências SUS como simples reforço para o orçamento municipal ou para outros fins que não a saúde; a "atomização" e a "pulverização" dos serviços de saúde decorrente da tendência de os municípios procurarem ter seu próprio hospital ou serviços; a ausência de cultura de gestão orientada para a economia de escala ou pela utilização de sistema de referência apropriado (World Bank, 1998). 
Quadro 1

Inovações trazidas pelo Piso de Atenção Básica (PAB).

(1) Alocação de uma parcela dos recursos federais voltados para o custeio de determinados procedimentos na rede pública de saúde.

(2) Incentivo ao desenvolvimento de ações e procedimentos de atenção básica e de medidas de promoção e prevenção em saúde.

(3) Reorganização da atenção básica com possível melhoria tanto nas condições de acesso, como na qualidade do atendimento prestado, especialmente visando aos municípios e às populações praticamente sem acesso aos serviços de saúde no começo da década de 1990.

(4) Indução de gradativa mudança no modelo assistencial com o desenvolvimento de programas inovadores, como o Saúde da Família.

(5) Definição de um conjunto de indicadores de processo e resultado para avaliação do impacto na qualidade da atenção associado ao PAB.

Os otimistas, como Vianna \& Piola (1999) sugeriram que um dos efeitos relevantes introduzidos pelos incentivos à maior autonomia decisória do gestor municipal no setor saúde brasileiro seria a ampliação da responsabilidade da instância local em relação aos recursos federais que lhes são transferidos.

Segundo os autores, no processo de descentralização brasileiro, as modalidades de habilitação vigentes no início da década de 1990, embora incentivassem o aumento da produção de serviços, criavam expectativas e pressões por mais recursos federais ao fortalecer, nas instâncias subnacionais, a cultura do provedor privado remunerado de acordo com a quantidade e densidade tecnológica de procedimentos.

Em meados da década de 1990, quando foi ampliada efetivamente a titularidade da gestão local pela NOB 01/96 teriam ficado bem evidentes os limites dos repasses federais face às necessidades de financiamento do sistema local, gerando "um incentivo natural à contenção de custos, ao uso de recursos próprios e uma maior responsabilidade pela gestão dos serviços” (Vianna \& Piola, 1999).

\section{O desenho metodológico do estudo}

Neste trabalho, utilizou-se um desenho longitudinal com o objetivo específico de oferecer evidências sobre os resultados do processo de implementação do PAB na qualidade da atenção à saúde nos municípios brasileiros.

O estudo de tendência tomou como unidade de análise a variável "município”. Os municí- pios aparecem agregados em variáveis de análise para identificar as associações entre certos atributos gerais (como porte populacional ou inserção regional) e indicadores de estrutura, processos e resultados da provisão da atenção à saúde decorrentes do processo de descentralização da atenção ambulatorial e básica.

Os diferentes agregados municipais brasileiros foram avaliados em dois momentos distintos da década de 1990 (anos de 1992 e 1999). O estudo utiliza esses agregados como unidade de referência para a definição da unidade de informação. As informações coletadas para as variáveis dependentes estão disponíveis nos bancos de dado resultantes dos inquéritos nacionais sobre estrutura da provisão de saúde - microdados das pesquisas sobre Assistência Médico-Sanitária de 1992 e 1999 realizadas pelo IBGE -, que permitem a desagregação pela unidade administrativa "município". Para construção da variável independente "porte populacional” foi utilizada a base de informação populacional das Pesquisas Nacionais por Amostra de Domicílios (PNADs), do IBGE (estimativas para os períodos intercensitários).

A opção metodológica de trabalhar com os bancos de dados já disponíveis para o diagnóstico da estrutura da provisão da atenção ambulatorial pareceu vantajosa para responder ao problema do impacto da descentralização da atenção básica sobre a estrutura dos serviços, em razão da facilidade de execução, baixo custo relativo e capacidade de responder às perguntas fundamentais. 


\section{Estrutura, processo e resultado da atenção à saúde}

Donabedian (1984) ofereceu um conjunto consistente de respostas metodológicas ao problema da avaliação de qualidade da atenção à saúde. Como medir os diferentes resultados da destinação de recursos públicos ao sistema de atenção à saúde?

As categorias básicas estrutura, processo e resultados (impactos) propostas pelo autor informam, como princípios gerais, as possibilidades de definição e mensuração específicas de variáveis de qualidade que podem resultar de processo de implementação de macropolíticas ou programas específicos na saúde. Essas categorias podem ser assim definidas:

Estrutura: compreende as condições (insumos e organização) obtidas ou disponíveis para o desenvolvimento das atividades previstas ou formuladas por uma política, programa ou projeto.

Processo: é considerado o conjunto de atividades que pode ser associado à estrutura disponível ou desenvolvida por uma política, programa ou projeto.

Resultado: refere-se à(s) mudança(s) na situação problema que pode $(\mathrm{m})$ ser associada(s) ou atribuída(s) às atividades de uma política, programa ou projeto.

Nesse estudo longitudinal retrospectivo focalizamos, inicialmente, as mudanças nas variáveis de estrutura, contemplando dois pontos específicos sobre a organização da atenção ambulatorial e básica municipal e os recursos humanos, descrevendo:

a) o impacto distributivo da política de ampliação de cobertura da atenção ambulatorial e de novos serviços de atenção primária - programas PSF e PACS - na estrutura de financiamento à saúde a partir da N0B 01/96, especialmente considerando os mecanismos de transferência definidos pelo Piso da Atenção Básica antes e depois de sua implantação;

b) a análise da variação no número de unidades e de empregos de nível superior, técnicos e auxiliares nos estabelecimentos sem internação do Sistema Único de Saúde (SUS) - tal como definidos pela pesquisa da AMS/IBGE 19921999. Essa categoria - estabelecimentos sem internação - compreende tanto unidades básicas de saúde como a rede ambulatorial. Ela será tomada como uma proxy das mudanças na oferta de força de trabalho na rede saúde de atenção básica. Berman (2000) comprova, nesse sentido, que a atenção ambulatorial, sob o ponto de vista do processo de trabalho médico, pode ser incorporada ao conjunto de atividades consideradas básicas para efeito de avaliação de desempenho dos sistemas de saúde nacionais.

A análise das variáveis de processo e resultado está analisada no Relatório Final do estudo referido (Costa et al., 2002).

\section{As evidências redistributivas do Piso Assistencial Básico}

Para responder ao ponto sobre o impacto distributivo da política pública de ampliação de cobertura na atenção básica, cabe apresentar as evidências observadas na destinação dos recursos públicos federais para os municípios entre os anos 1997-1999 (antes e depois da implantação do PAB).

O que pode ser evidenciado, inicialmente, é que o processo de descentralização no período mencionado teve como característica básica a redistribuição dos recursos para a atenção bási$\mathrm{ca}$, favorecendo os municípios de pequeno porte e reduzindo expressivamente as diferenças regionais em relação ao financiamento federal para essa função da atenção à saúde.

Para análise dos dados relativos ao volume de recursos transferidos pelo Ministério da Saúde para o conjunto de municípios brasileiros entre 1997 e 1999, foi criado um banco de dados com as informações obtidas junto aos sistemas de informação do IBGE e do DATASUS/MS.

O Ministério da Saúde realizou um estudo em 1997, com os dados do SIA-SUS de 1996, com o objetivo de definir aquilo que em 1998 seria chamado de procedimentos de atenção básica (procedimentos PAB). Esse grupo de procedimentos gerou a variável "PAB anterior" para o ano de 1997, considerada por este estudo.

O Datasus disponibilizou, na página do Ministério da Saúde, em 2000, informações municipais para esta última variável ("PAB anterior"), relativa à soma de todos os procedimentos ajustados para 1997 e o "PAB atual", resultado de uma projeção realizada para 1999, a partir das hipóteses de elevação do PAB per capita para $\mathrm{R} \$ 10,00$, no caso de municípios habilitados com valor anterior inferior a esse patamar; manutenção dos mesmos valores do PAB per capi$t a$, no caso de municípios habilitados com valor entre $\mathrm{R} \$ 10,00$ e $\mathrm{R} \$ 18,00$ e, limitação do PAB per capita em $\mathrm{R} \$ 18,00$, no caso de municípios habilitados com valor superior a essa cifra. Além 
disso, foram levantados também, no ano de 2000, os dados relativos ao "PAB realizado" (Tabela 1).

Os dados coletados demonstram um aumento real, de cerca de $34 \%$, do valor do PAB total no período antes e depois de sua implantação (1997 x 1999), passando de R $\$ 1$,2 bilhão para $\mathrm{R} \$ 1,6$ bilhão. $\mathrm{Na}$ análise dos dados referentes aos municípios habilitados no $\mathrm{PAB}$, não foram consideradas cinco cidades que apresentavam o nome do município como "ignorado", embora constassem valores repassados pelo Governo Federal a esses municípios. Em cada unidade da federação também se mantém esse comportamento do país, isto é, houve um acréscimo do valor do PAB per capita para o conjunto dos municípios, não apenas antes e depois de sua implantação, como também entre o valor projetado e o valor efetivamente realizado no ano de 1999. Cabe assinalar que os municípios de algumas unidades da federação já recebiam em 1997, repasses federais médios superiores a R \$10,00 per capita: Paraná, Piauí, Mato Grosso e Minas Gerais (Figura 1).

Outra questão a ser evidenciada pelos dados são os comportamentos das transferências fede-

\section{Tabela 1}

Distribuição dos valores do PAB anterior (1997), projetado e realizado para 1999 segundo unidades da federação e grandes regiões - Brasil - 1997 x 1999.

\begin{tabular}{|c|c|c|c|c|c|c|c|}
\hline \multirow{2}{*}{$\begin{array}{l}\text { Unidades da } \\
\text { Federação }\end{array}$} & \multirow[b]{2}{*}{$\begin{array}{l}\text { Número de } \\
\text { municípios }\end{array}$} & \multicolumn{2}{|c|}{1997} & \multicolumn{2}{|c|}{1999} & \multicolumn{2}{|c|}{1999} \\
\hline & & $\begin{array}{l}\text { "PAB" } \\
\text { anterior }\end{array}$ & $\begin{array}{c}\text { "PAB" anterior } \\
\text { per capita }\end{array}$ & $\begin{array}{c}\text { PAB } \\
\text { projetado }\end{array}$ & $\begin{array}{l}\text { PAB projetado } \\
\text { per capita }\end{array}$ & $\begin{array}{l}\mathrm{PAB} \\
\text { realizado }\end{array}$ & $\begin{array}{c}\text { PAB realizado } \\
\text { per capita }\end{array}$ \\
\hline Acre & 18 & $2.870 .399,07$ & 5,98 & $4.796 .610,00$ & 9,45 & $4.487 .106,53$ & 9,75 \\
\hline Amazonas & 51 & $12.426 .973,10$ & 5,34 & $23.295 .963,20$ & 9,54 & $22.574 .850,10$ & 9,87 \\
\hline Amapá & 14 & $2.787 .175,90$ & 7,07 & $4.173 .756,90$ & 9,66 & $4.126 .668,25$ & 9,96 \\
\hline Pará & 134 & $29.725 .404,10$ & 5,36 & $56.521 .836,10$ & 9,78 & $56.692 .652,21$ & 10,04 \\
\hline Rondônia & 52 & $9.964 .495,80$ & 7,94 & $13.437 .397,20$ & 10,36 & $13.592 .380,24$ & 10,48 \\
\hline Roraima & 12 & $1.838 .862,00$ & 7,69 & $2.432 .215,20$ & 9,68 & $2.412 .997,86$ & 9,96 \\
\hline Tocantins & 138 & $8.429 .947,30$ & 7,83 & $11.759 .504,60$ & 10,4 & $12.043 .753,02$ & 10,65 \\
\hline Região Norte & 419 & $68.043 .257,27$ & 6,01 & $116.417 .283,20$ & 9,83 & $115.930 .408,21$ & 10,10 \\
\hline Alagoas & 101 & $25.522 .798,20$ & 9,58 & $30.238 .540,60$ & 11,14 & $30.335 .415,67$ & 11,18 \\
\hline Bahia & 404 & $65.563 .604,70$ & 5,23 & $127.170 .344,30$ & 9,93 & $126.950 .908,93$ & 10,09 \\
\hline Ceará & 183 & $66.878 .735,16$ & 9,68 & $76.003 .397,00$ & 10,72 & $76.315 .010,58$ & 10,86 \\
\hline Maranhão & 212 & $42.590 .386,30$ & 8,10 & $59.665 .616,20$ & 11,1 & $57.824 .900,17$ & 11,10 \\
\hline Paraíba & 213 & $29.597 .437,20$ & 9,01 & $36.110 .841,40$ & 10,85 & $35.544 .508,99$ & 10,82 \\
\hline Pernambuco & 185 & $72.762 .928,90$ & 9,74 & $89.358 .551,80$ & 11,79 & $89.836 .795,29$ & 11,85 \\
\hline Piauí & 219 & $28.125 .678,20$ & 10,51 & $32.982 .606,00$ & 12,15 & $32.205 .781,59$ & 12,23 \\
\hline Rio Grande do Norte & 164 & $22.287 .388,90$ & 8,65 & $27.149 .821,10$ & 10,29 & $27.404 .306,98$ & 10,39 \\
\hline Sergipe & 74 & $16.262 .302,00$ & 9,83 & $20.373 .660,20$ & 11,92 & $20.607 .781,79$ & 12,06 \\
\hline Região Nordeste & 1.755 & $369.591 .259,56$ & 8,21 & $499.053 .378,60$ & 10,86 & $497.025 .409,99$ & 10,95 \\
\hline Espírito Santo & 73 & $13.396 .767,05$ & 4,76 & $28.443 .880,80$ & 9,81 & $28.500 .463,04$ & 9,98 \\
\hline Minas Gerais & 825 & $170.472 .714,20$ & 10,18 & $192.341 .736,50$ & 11,22 & $191.756 .217,80$ & 11,29 \\
\hline Rio de Janeiro & 91 & $92.647 .944,50$ & 6,83 & $139.569 .753,20$ & 10,11 & $140.138 .031,95$ & 10,20 \\
\hline São Paulo & 613 & $220.004 .203,90$ & 9,00 & $261.368 .036,40$ & 10,29 & $261.528 .681,98$ & 10,48 \\
\hline Região Sudeste & 1.602 & $496.521 .629,65$ & 8,63 & $621.723 .406,90$ & 10,49 & $621.923 .394,77$ & 10,63 \\
\hline Paraná & 399 & $101.629 .656,40$ & 11,12 & $109.377 .082,30$ & 11,67 & $110.339 .852,70$ & 11,77 \\
\hline Rio Grande do Sul & 441 & $49.038 .157,20$ & 5,11 & $96.688 .008,80$ & 9,87 & $96.222 .165,16$ & 10,00 \\
\hline Santa Catarina & 292 & $33.957 .269,74$ & 6,85 & $51.400 .449,40$ & 10,09 & $51.502 .298,02$ & 10,18 \\
\hline Região Sul & 1.132 & $184.625 .083,34$ & 7,79 & $257.465 .540,50$ & 10,61 & $258.064 .315,88$ & 10,73 \\
\hline Distrito Federal & 1 & $13.262 .341,30$ & 7,07 & $18.770 .150,00$ & 9,53 & $19.272 .957,16$ & 9,78 \\
\hline Goiás & 242 & $32.003 .014,80$ & 6,90 & $48.705 .746,70$ & 10,05 & $49.911 .807,74$ & 10,30 \\
\hline Mato Grosso do Sul & 77 & $14.041 .593,40$ & 7,15 & $19.800 .538,80$ & 9,77 & $19.958 .332,87$ & 9,96 \\
\hline Mato Grosso & 126 & $23.306 .249,50$ & 10,19 & $26.828 .858,80$ & 11,29 & $27.227 .309,92$ & 11,46 \\
\hline Região Centro-Oeste & 446 & 82.613.199,00 & 7,67 & $114.105 .294,30$ & 10,17 & $116.370 .407,69$ & 10,39 \\
\hline Brasil & 5.354 & $1.201 .394 .428,82$ & 8,10 & $1.608 .764 .903,50$ & 10,55 & $1.609 .313 .936,54$ & 10,68 \\
\hline
\end{tabular}

Fonte: Tabela elaborada a partir dos dados disponibilizados pelo IBGE, Pesquisa Nacional por Amostra de Domicílios (PNAD), 1997 e 1999 e Datasus/Ministério da Saúde, 2000. Nota: A tabela não considera os 143 municípios que não estavam habilitados em uma das duas condições de gestão segundo a NOB-96. Foram excluídos cinco municípios, cujo código do município do IBGE era "ignorado". 
Figura 1

Distribuição do PAB anterior (1997) e realizado para 1999 segundo unidades da federação e grandes regiões - Brasil - 1997 X 1999.

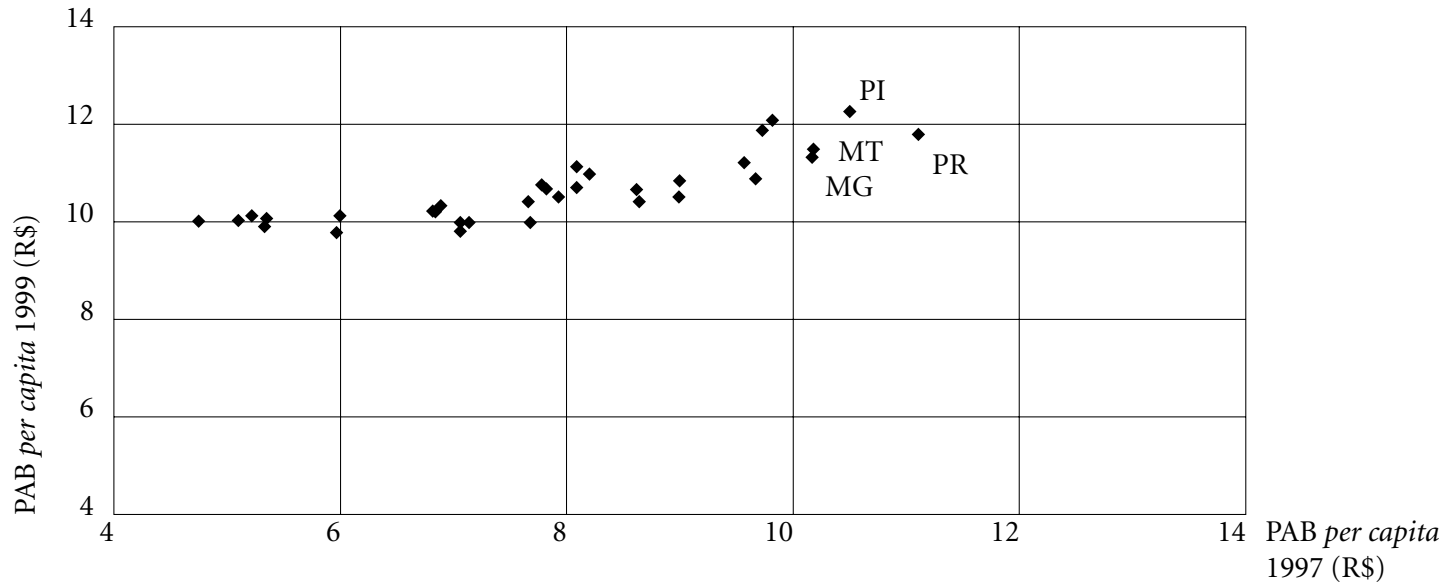

Fonte: Figura elaborada a partir da tabela 1. Para os dados populacionais, IBGE, Pesquisa Nacional por Amostra de Domicílios (PNAD), 1997 e 1999. Para as informações do PAB, Datasus/Ministério da Saúde, 2000.

Nota: A tabela não considera os 148 municípios que não estavam habilitados em uma das duas condições de gestão segundo a NOB-96. Foram excluídos cinco municípios, cujo código do município do IBGE era "ignorado".

rais per capita/ano antes e depois da implantação do PAB. A análise exploratória ajuda a responder essa questão (Quadro 2).

A partir do quadro 2, podemos observar que, antes da implantação do PAB:

1) os municípios das regiões Nordeste e Sul apresentavam valores com grande variabilidade; 2) o primeiro quartil, que corresponde aos $25 \%$ dos municípios que recebiam as menores transferências federais, oscilou entre $\mathrm{R} \$ 1,00 \mathrm{e}$ $\mathrm{R} \$ 3,00$, para as regiões Norte, Nordeste e Sul, representando o pior desempenho desta estatística entre as regiões brasileiras;

3) os municípios da região Sudeste foram os que apresentaram a maior concentração de valores mais elevados, entre $\mathrm{R} \$ 6,00$ e $\mathrm{R} \$ 11,00$;

4) os municípios da região Centro-Oeste exibiam um comportamento semelhante àqueles observados no Sudeste, porém num patamar inferior, com valores variando principalmente entre $\mathrm{R} \$ 4,00$ e $\mathrm{R} \$ 11,00$.

Por outro lado, após a implantação do PAB em 1999, percebe-se que:

1) os municípios de todas as regiões brasileiras elevaram o valor do $\mathrm{PAB}$ per capita/ano para um valor igual ou próximo a $\mathrm{R} \$ 10,00$ e apresentam uma dispersão menor que o valor do $\mathrm{PAB}$ anterior;

2) os municípios da região Norte apresentam a menor média, $\mathrm{R} \$ 10,57$;
3) comparativamente, os valores realizados do $\mathrm{PAB}$ per capita estão mais concentrados em torno da média nos municípios das regiões Norte $(d p=1,77)$, Nordeste $(d p=1,96)$, Sudeste $(d p=$ $2,38)$, Centro-Oeste $(\mathrm{dp}=2,66)$ e Sul $(\mathrm{dp}=2,68)$; onde "dp", representa o desvio-padrão populacional, ou seja, expressa a variabilidade da transferência federal recebida em relação ao valor médio para cada região.

O coeficiente de variação da destinação de recursos para os municípios tornou-se bastante homogêneo entre as regiões do país, após a implantação do $\mathrm{PAB}$, com especial destaque para as regiões Norte e Nordeste. A diminuição da dispersão relativa do total de recursos destinados à atenção básica, no período antes e depois da implantação do PAB, em todas as regiões do Brasil, evidencia o impacto redistributivo Piso de Atenção Básica (PAB), com valores medianos em torno de $\mathrm{R} \$ 10,00$ per capita/ano (Tabela 2).

Para a comparação dos municípios brasileiros em cada unidade da federação/região, além de se considerar o valor das transferências do PAB fixo per capita para o ano de 1999 e o conjunto de procedimentos que se convencionou chamar de "PAB" per capita para o ano de 1997, foram criados três subgrupos:

G1: municípios que ganhavam em 1997, menos de $\mathrm{R} \$ 10,00$ per capita/ano e que passaram a ganhar em 1999, cerca de $\mathrm{R} \$ 10,00$ per ca- 
pita/ano (“municípios que mais ganharam”, em número de 3.707);

G2: municípios que ganhavam em 1997, mais de $\mathrm{R} \$ 10,00$ per capita/ano e menos de $\mathrm{R} \$ 18,00$ per capita/ano, e que passaram a ganhar em 1999, valores nesse mesmo intervalo ("municípios que ganharam valores proporcionais ao intervalo $\mathrm{R} \$ 10,00$ e a $\mathrm{R} \$ 18,00$ ”, em número de 547);

G3: municípios que ganhavam em 1997, mais de $\mathrm{R} \$ 18,00$ per capita/ano e que passaram a ganhar em 1999, até $\mathrm{R} \$ 18,00$ per capita/ano ("municípios que perderam”, em número de 1.100).

As regiões Norte e Nordeste foram as que mais se beneficiaram com a nova forma de transferência dos recursos do Ministério da Saúde para atenção básica: cerca de $80 \%$ dos municípios dessas localidades estão no subgrupo 1 . Os subgrupos de receita per capita correspondem aos grupos de municípios classificados segundo as transferências do PAB fixo dos anos de 1997 e 1999. Os municípios do subgrupo G1 recebiam em 1997 valores per capita próximo de $\mathrm{R} \$ 0$ (zero) e passaram a ter cerca de $\mathrm{R} \$ 10,00$ per capita em 1999.

Por outro lado, a região Sudeste foi a que mais perdeu recursos, ou seja, “apenas", 58,5\% dos municípios localizam-se no grupo 1 , e $31,0 \%$ estão no grupo 3, ou seja, recebiam em 1997 valores per capita/ano acima de R $\$ 18,00$ e passaram a ganhar no máximo $\mathrm{R} \$ 18,00$. A região Sul representa o local, cujos municípios tiveram uma das maiores quedas no volume de transferências no PAB (por exemplo, o Paraná apresenta $41,4 \%$ das localidades classificadas no subgrupo 3). Além disso, o Amapá (42,9\%), São Paulo (38,3\%), Mato Grosso (32,5\%) foram outras unidades da federação com grandes reduções nesse tipo de receita.

No Brasil como um todo, os municípios que mais se beneficiaram com a redistribuição de recursos promovida pelo Ministério da Saúde através do PAB (soma dos percentuais de G1 e G2) foram os povoados com menos de 50.000 habitantes. Em contrapartida, cerca de $30 \%$ das cidades com mais de 50.000 habitantes tiveram o montante de recursos reduzidos. Além de ter sido elevada, a distribuição dos recursos passou a ter um aspecto mais homogêneo em torno de um valor central (Tabela 3).
Quadro 2

Estatísticas descritivas das transferências per capita para a atenção básica no ano de 1999 segundo grandes regiões Brasil - 1999.

Região Norte

\begin{tabular}{lrrlrrr}
\multicolumn{3}{c}{ Variable=PABCAP99 } & \multicolumn{3}{c}{ PAB $^{\star}$ realizado* per capita } \\
\hline \multicolumn{3}{c}{ Moments } & \multicolumn{4}{c}{ Quantiles } \\
$\mathrm{N}$ & 419 & $100 \%$ & Max & 19.48083 & $99 \%$ & 18.09714 \\
Mean & 10.56707 & $75 \%$ & Q3 & 10.53718 & $95 \%$ & 15.19551 \\
Std & 1.766742 & $50 \%$ & Med & 9.909787 & $90 \%$ & 12.23848 \\
Dev & & $25 \%$ & Q1 & 9.756135 & $10 \%$ & 9.570128 \\
& & $0 \%$ & Min & 8.640732 & $5 \%$ & 9.482172 \\
& & & & & $1 \%$ & 9.232028
\end{tabular}

Região Sul

Variable $=$ PABCAP99 $\quad$ PAB $^{\star}$ realizado $^{\star}$ per capita

\begin{tabular}{lrrlrrr}
\hline \multicolumn{3}{c}{ Moments } & & \multicolumn{3}{c}{ Quantiles } \\
N & 1132 & $100 \%$ & Max & 18.77201 & $99 \%$ & 18.76819 \\
Mean & 11.42264 & $75 \%$ & Q3 & 11.15532 & $95 \%$ & 18.17814 \\
Std & 2.677391 & $50 \%$ & Med & 10.0793 & $90 \%$ & 16.69158 \\
Dev & & $25 \%$ & Q1 & 9.926163 & $10 \%$ & 9.784531 \\
& & $0 \%$ & Min & 9.173529 & $5 \%$ & 9.758134 \\
& & & & & $1 \%$ & 9.685144 \\
\hline
\end{tabular}

\begin{tabular}{|c|c|c|c|c|c|c|}
\hline \multicolumn{4}{|c|}{ Região Nordeste } & \multicolumn{3}{|c|}{$\mathrm{PAB}^{\star}$ realizado ${ }^{\star}$ per capita } \\
\hline \multicolumn{4}{|c|}{ Moments } & \multicolumn{3}{|c|}{ Quantiles } \\
\hline $\mathrm{N}$ & 1755 & $100 \%$ & $\operatorname{Max}$ & 18.55844 & $99 \%$ & 18.0603 \\
\hline Mean & 10.85706 & $75 \%$ & Q3 & 10.63882 & $95 \%$ & 16.27802 \\
\hline Std & 1.959088 & $50 \%$ & Med & 10.00269 & $90 \%$ & 13.51718 \\
\hline \multirow[t]{3}{*}{ Dev } & & $25 \%$ & Q1 & 9.907372 & $10 \%$ & 9.785647 \\
\hline & & $0 \%$ & Min & 8.872437 & $5 \%$ & 9.716412 \\
\hline & & & & & $1 \%$ & 9.676402 \\
\hline
\end{tabular}

(continua)

\section{Avaliação do impacto dos incentivos da descentralização na estrutura da atenção básica nos municípios brasileiros}

Nesta parte é avaliada a situação da estrutura da rede básica municipal brasileira na década de 1990 para evidenciar as condições de desenvolvimento da estratégia de ampliação de cobertura, acesso e mudança de modelo assistencial definida pelo PAB.

Os dados originados pelas pesquisas de Assistência Médico-Sanitária (AMS/IBGE, 1992 e 1999) apontam, de modo geral, que o processo de municipalização dos serviços de saúde desencadeado a partir da implantação do Sistema 
Quadro 2

Continuação

\begin{tabular}{lrrlrrr}
\multicolumn{2}{l}{$\begin{array}{l}\text { Região Centro-Oeste } \\
\text { Variable=PABCAP99 }\end{array}$} & \multicolumn{3}{c}{ PAB $^{\star}$ realizado ${ }^{\star}$ per capita } \\
\hline \multicolumn{4}{r}{ Moments } & & \multicolumn{3}{c}{ Quantiles } \\
N & 446 & $100 \%$ & Max & 29.81797 & $99 \%$ & 18.61723 \\
Mean & 11.19241 & $75 \%$ & Q3 & 10.84124 & $95 \%$ & 17.60899 \\
Std & 2.657143 & $50 \%$ & Med & 9.970363 & $90 \%$ & 15.95185 \\
Dev & & $25 \%$ & Q1 & 9.800516 & $10 \%$ & 9.676645 \\
& & $0 \%$ & Min & 8.513176 & $5 \%$ & 9.524697 \\
& & & & & $1 \%$ & 9.394406
\end{tabular}

\section{Região Sudeste}

Variable $=$ PABCAP 99

\begin{tabular}{lrrlrrr}
\hline & \multicolumn{3}{c}{ Moments } & & \multicolumn{3}{c}{ Quantiles } \\
$\mathrm{N}$ & 1602 & $100 \%$ & Max & 18.33626 & $99 \%$ & 18.30303 \\
Mean & 11.28744 & $75 \%$ & Q3 & 11.6365 & $95 \%$ & 17.49455 \\
Std & 2.375942 & $50 \%$ & Med & 10.05773 & $90 \%$ & 15.58577 \\
Dev & & $25 \%$ & Q1 & 9.894597 & $10 \%$ & 9.803867 \\
& & $0 \%$ & Min & 9.397391 & $5 \%$ & 9.744169 \\
& & & & & $1 \%$ & 9.679146 \\
\hline
\end{tabular}

Brasil

\begin{tabular}{|c|c|c|c|c|c|c|}
\hline \multicolumn{4}{|c|}{ Variable $=$ PABCAP99 } & \multicolumn{3}{|c|}{$\mathrm{PAB}^{\star}$ realizado* per capita } \\
\hline \multicolumn{4}{|c|}{ Moments } & \multicolumn{3}{|c|}{ Quantiles } \\
\hline $\mathrm{N}$ & 5354 & $100 \%$ & $\operatorname{Max}$ & 29.81797 & $99 \%$ & 18.45285 \\
\hline Mean & 11.11062 & $75 \%$ & Q3 & 10.8932 & $95 \%$ & 17.48079 \\
\hline Std & 2.316464 & $50 \%$ & Med & 10.0427 & $90 \%$ & 14.92423 \\
\hline \multirow[t]{3}{*}{ Dev } & & $25 \%$ & Q1 & 9.892842 & $10 \%$ & 9.763942 \\
\hline & & $0 \%$ & Min & 8.513176 & $5 \%$ & 9.712499 \\
\hline & & & & \multicolumn{3}{|c|}{$1 \% 9.48567$} \\
\hline
\end{tabular}

Fonte: Ministério da Saúde/DATASUS, 2000.

Tabela 2

Coeficiente de variação do total de recursos destinados à atenção básica nos municípios brasileiros - Brasil 1997 x 1999.

\begin{tabular}{lcc}
\hline Grandes regiões & $\mathbf{1 9 9 7}$ & $\mathbf{1 9 9 9}$ \\
\hline Norte & $98,4 \%$ & $16,7 \%$ \\
Nordeste & $79,6 \%$ & $18,0 \%$ \\
Sudeste & $59,1 \%$ & $21,0 \%$ \\
Sul & $81,0 \%$ & $23,5 \%$ \\
Centro-Oeste & $73,9 \%$ & $23,7 \%$ \\
Brasil & $74,8 \%$ & $20,8 \%$ \\
\hline
\end{tabular}

Fonte: Ministério da Saúde/DATASUS, 2000.
Único de Saúde, em 1988, levou a uma rápida mudança na estrutura do setor público municipal no Brasil.

No período de 1992-1999, os estabelecimentos de saúde de natureza municipal experimentaram uma taxa geométrica de crescimento anual, muito superior às demais unidades de saúde dos outros níveis federativos, com a transferência de estabelecimentos federais e estaduais, processando-se de forma diferente em cada região do país. Nesse processo, os estabelecimentos de saúde sem internação de natureza pública que prestam serviços de atenção básica e ambulatorial passaram a representar $23 \%$ dos municípios existentes no país, com destaque para as localidades de menos de 5.000 habitantes. Nesses locais, o crescimento da rede pode ser definido claramente como uma rede de unidades básicas de baixa capacidade tecnológica.

As variáveis da pesquisa de Assistência Médico-Sanitária (AMS) foram criticadas e reagrupadas conforme cada situação, a fim de tornar possível a análise dos dados entre 1992 e 1999 de forma comparada. Esses dois períodos correspondem às duas últimas versões do inquérito realizado em caráter nacional e censitário pelo IBGE, em todos os municípios brasileiros instalados no momento da pesquisa. $\mathrm{O}$ universo de análise exclui apenas os consultórios e ambulatórios particulares (médicos e dentários), típicos das cidades de mais de 200.000 habitantes, estabelecimentos criados em caráter de campanha, unidades que se dediquem exclusivamente à pesquisa e/ou ensino e laboratórios de análises clínicas que prestam serviço exclusivo nessa área.

Salienta-se que as variáveis disponibilizadas pelo IBGE relativas à AMS/1992 apresentam-se em quantidade reduzida quando comparadas ao ano de 1999. Com isso, algumas dimensões não poderão ser analisadas, como por exemplo, o número de empregos por categoria profissional. Além disso, o próprio questionário de 1992 possuía um número muito inferior de perguntas se comparado ao ano de 1999.

$\mathrm{Na}$ análise da questão dos recursos humanos foi considerada a estratificação do número de empregos de cada categoria profissional segundo o nível de escolaridade, tal como divulgado na AMS/1992. Além dos empregos médicos (anestesista, cirurgião, clínico geral, ginecoobstetra, médico de família, físico médico, pediatra, psiquiatra, radiologista, médico-residente, sanitarista, e outras especialidades médicas), três outros estratos foram criados: 1) empregos 
Tabela 3

Distribuição dos municípios habilitados no PAB em dezembro/1999 por subgrupos de receita PAB fixo per capita e porte do município - Brasil - 1999.

\begin{tabular}{lrrrrrrrr}
\hline Porte do Município & G1 & $\mathbf{( \% )}$ & G2 & $\mathbf{( \% )}$ & G3 & (\%) & Total & (\%) \\
\hline até 10.000 hab. & 1.769 & 68,04 & 338 & 13,00 & 493 & 18,96 & 2.600 & 100,00 \\
de 10.001 a 50.000 hab. & 1.588 & 70,33 & 200 & 8,86 & 470 & 20,81 & 2.258 & 100,00 \\
de 50.001 a 100.000 hab. & 194 & 68,79 & 6 & 2,13 & 82 & 29,08 & 282 & 100,00 \\
de 100.001 a 200.000 hab. & 80 & 70,80 & 1 & 0,88 & 32 & 28,32 & 113 & 100,00 \\
Mais de 200.000 hab. & 76 & 75,25 & 2 & 1,98 & 23 & 22,77 & 101 & 100,00 \\
Total & 3.707 & 69,24 & 547 & 10,22 & 1.100 & 20,55 & 5.354 & 100,00 \\
\hline
\end{tabular}

Fontes: Datasus/MS e IBGE, 1999.

de profissionais de nível superior exceto médicos (assistente social, bioquímico/farmacêutico, enfermeiro, engenheiro clínico, fisioterapeuta, fonoaudiólogo, nutricionista, odontólogo, psicólogo, outros profissionais de nível superior); 2) empregos de profissionais de nível técnico com e sem diploma (técnico de enfermagem, técnico de farmácia, técnico em hematologia/ hemoterapia, técnico em histologia, técnico em nutrição e dietética, técnico em patologia clínica, técnico em reabilitação, técnico em vigilância sanitária e ambiental, técnico em citologia/citotécnica, técnico em equipamentos médico-hospitalares, técnico em higiene dental, técnico em prótese dentária, técnico em radiologia médica, outros técnicos); e 3 ) empregos de profissionais de nível auxiliar com e sem diploma (agente de saneamento, auxiliar de consultório dentário, auxiliar de enfermagem, fiscal sanitário, auxiliar de farmácia, auxiliar em hematologia/hemoterapia, auxiliar em histologia, auxiliar em nutrição e dietética, auxiliar em patologia clínica, auxiliar em reabilitação, auxiliar em vigilância sanitária e ambiental, agente comunitário de saúde, agente de saúde pública, atendente de enfermagem, guarda de endemias, parteira e outros profissionais de nível elementar).

Os empregos de profissionais em funções administrativas, que inclui, além do pessoal que atua em áreas administrativas, profissionais do serviço de limpeza, conservação e segurança, não foram considerados na análise dos dados sobre recursos humanos em saúde, que ora apresentamos.

Uma importante característica da década de 1990 foi o persistente crescimento do número de novos municípios instalados em todas as regiões do país - cerca de 1.000, entre 1992 e 1999. Cabe sublinhar o especial crescimento dos municípios muito pequenos - com até 5 mil habi- tantes -, que apresentaram um incremento de $73 \%$; os entre 5 e 10 mil habitantes foram ampliados em $28 \%$. Os municípios na faixa de 10 a 20 mil habitantes cresceram em $12 \%$ e os acima desse limiar tiveram um crescimento mais moderado - média de 2,6\% entre os dois períodos, ainda que 32 novos municípios com mais de 20 mil habitantes tenham sido criados no país entre 1992 e 1999.

Embora se argumente que esse processo esteja relacionado aos incentivos oriundos da Constituição de 1988, que teria favorecido a fragmentação administrativa, a iniciativa da fragmentação dos municípios é uma característica da tradição da gestão pública local brasileira. Em 1940 existiam pouco mais de 1.500 municípios no país. Ao longo das décadas, a tendência foi de um crescimento explosivo. Entre 1940 e 1963, por exemplo, os 2.029 novos municípios foram criados com um perfil de pequenas cidades. A consolidação dessa tendência nas décadas seguintes (períodos entre 1963-1988; 1988-1992; 1993-1996; 1997-1999) configurou a situação atual dos municípios brasileiros, formado em sua maioria por municípios de menos de 20.000 habitantes (74,8\% do total em 1999). Ao mesmo tempo em que os municípios com população acima de 20.000 habitantes têm apresentado, desde a década de 1960, um crescimento residual.

A hipótese central em relação à tendência à fragmentação administrativa dos municípios é considerar se essa fragmentação poderia afetar o desempenho da descentralização e inviabilizar a ampliação da estrutura para a atenção básica, acrescentando o item da fragmentação administrativa ao conjunto de pontos assinalados como risco à performance na qualidade da atenção à saúde. 


\section{A expansão do número de estabelecimentos sem internação}

Um primeiro ponto que pode ser respondido a respeito da descentralização é a expansão da oferta de unidades ambulatoriais e básicas de saúde entre 1992 e 1999. Os dados demonstram que a distribuição do número médio de estabelecimentos nos municípios entre os dois períodos se alterou ligeiramente. Em 1999, nos municípios de menos de 2.000 habitantes, o número médio de estabelecimentos era de 1,35 por município; nas cidades entre 2.001 e 5.000 habitantes, este valor correspondia a 1,79; entre 5.001 e 10.000 habitantes, 2,82; entre 10.001 habitantes e 20.000 habitantes, 4,56; entre 20.001 habitantes e 80.000 habitantes, 9,14; entre 80.001 e 200.000 habitantes, 18,33; e nas grandes cidades, com mais de 200.000 habitantes, 41,97. Essa distribuição é muito semelhante à encontrada em 1992, exceto para os municípios entre 80.000 e 200.000 habitantes que tiveram visível incremento de serviços básicos na década.

A natureza das mudanças na estrutura dos serviços fica demonstrada pela figura 2, que evidencia um aumento significativo do número de municípios com estabelecimentos básicos ou ambulatoriais de saúde em todas as regiões brasileiras, ou seja, a existência de uma unidade básica de saúde de natureza pública é um resul- tado importante da descentralização, especialmente para os municípios de menos de 5.000 habitantes.

Essa tendência de aumento da oferta ambulatorial e básica não é homogênea quando as regiões são analisadas detalhadamente. A fragmentação municipal tem afetado particularmente alguns estados do Norte e Nordeste, que apresentam uma grande proporção de municípios sem estabelecimentos básicos ou ambulatoriais de saúde, como é o caso de Rondônia, Roraima e Tocantins.

Quando analisado na perspectiva da população residente dos municípios, estabelecendo uma razão entre número de estabelecimentos por 10.000 habitantes, os dados evidenciam que houve um crescimento da oferta de serviços básicos e ambulatoriais no país como um todo entre 1992 e 1999 (Tabela 4).

Quando focalizados sob a perspectiva dos estados e dos estratos municipais, torna-se evidente que os ganhos líquidos da descentralização até o ano de 1999 foram também diferenciados, ocorrendo casos de sistemática diminuição da oferta pública de atenção à saúde, podendose observar entre o período considerado:

- um decréscimo na disponibilidade desses serviços no estado do Amazonas, especialmente nos pequenos municípios (até 10 mil habitantes);

Figura 2

Proporção de municípios com estabelecimentos de saúde - Brasil - 1992 x 1999.

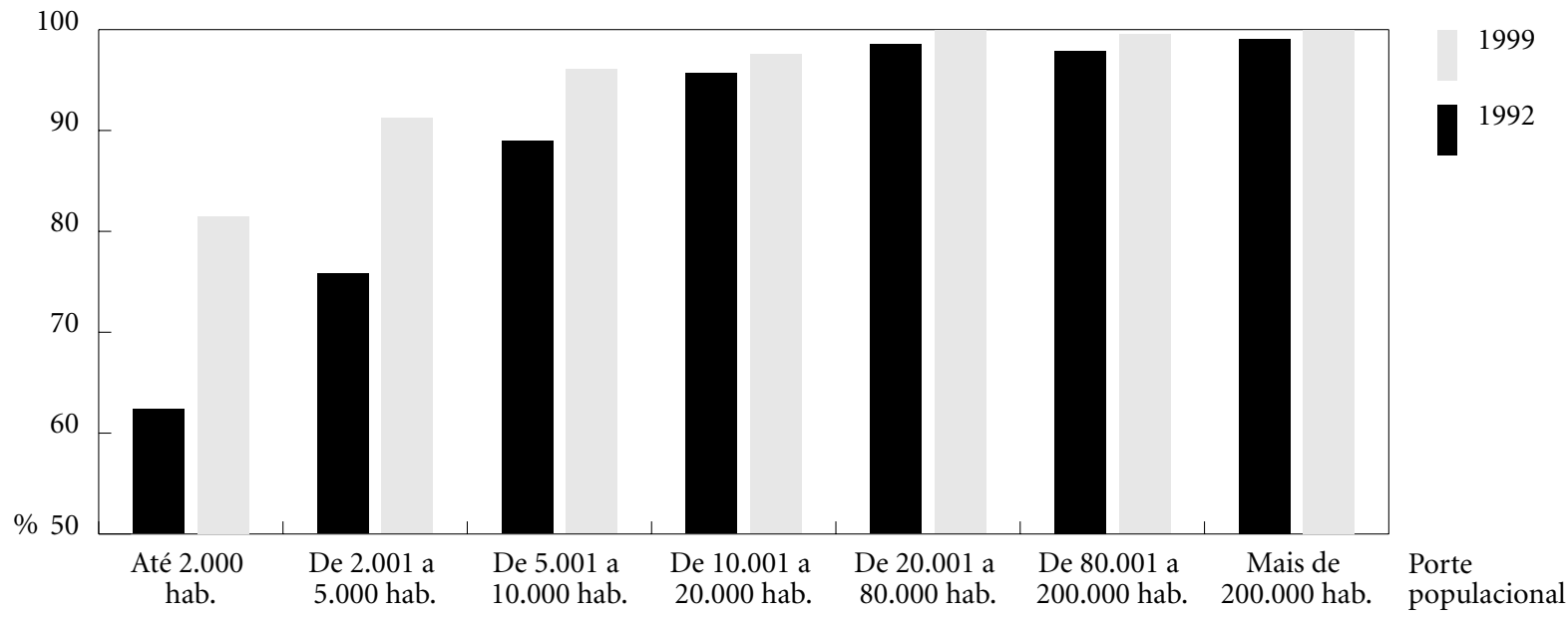

Fonte: Tabela criada a partir dos microdados da pesquisa AMS/1992 e 1999, IBGE. 
- uma redução na oferta de serviços identificada em municípios do Nordeste nos estados do Piauí, Ceará, Paraíba e Sergipe;

- uma sistemática queda na oferta de serviços públicos básicos e ambulatoriais nos municípios dos estados do Espírito Santo e São Paulo;

A figura 3 e a tabela 5 demonstram o processo de encolhimento ou estagnação na oferta ambulatorial vinculada a alguns municípios brasileiros. Ela parece ter sido amplamente compensada pelo crescimento ambulatorial e básico do segmento prestador de serviços para os planos e seguros de saúde (não SUS). Pode-se afirmar que a característica da década de 1990 foi o notável crescimento da atenção ambulatorial e básica nos pequenos municípios brasileiros e o crescimento equivalente desse nível de atenção no setor de seguro saúde (não SUS) nas médias e grandes cidades.

\section{Evolução do emprego}

Os dados da evolução do número de empregos oferecem evidências adicionais sobre as características da mudança na estrutura dos sistemas locais de atenção básica e ambulatorial que obser- varam o maior crescimento relativo no período 1992/1999, seguidos pelos empregos em unidades com internação. $O$ período considerado registra ainda uma queda dos empregos em unidades de apoio à diagnose e terapia (Tabela 6).

Além disso, como demonstra a tabela 7 , a variação no emprego na atenção básica e ambulatorial é inversamente associada ao porte populacional do município quando analisados os dados para o total do país: quanto menor o município, maior foi, proporcionalmente, o número de empregos criados na funcão de atenção à saúde. Todas as regiões do país demonstram essa tendência.

A análise por estado da Federação e pelo porte populacional dos municípios também confirma essa descrição, como algumas situações diferenciadas que cabe sublinhar:

- Os estratos municipais de pequeno porte que tiveram um crescimento expressivo no número de empregos na rede básica e ambulatorial, com incrementos sistematicamente superiores aos verificados no país. Alguns estratos de municípios entre 80 e 200 mil habitantes em estados principalmente da região Nordeste apresentam um comportamento discrepante porque registram decréscimo ou crescimento

Tabela 4

Estabelecimentos de saúde sem internação e número de unidades por 10.000 habitantes segundo porte do município - Brasil - 1992/1999.

\begin{tabular}{lccc}
\hline $\begin{array}{l}\text { Porte populacional } \\
\text { (em habitantes) }\end{array}$ & No de municípios $\left(^{*}\right)$ & $\begin{array}{c}\text { No de unidades } \\
\text { de saúde }\end{array}$ & $\begin{array}{c}\text { No de unidades } \\
\text { por10.000 hab. }\end{array}$ \\
\hline $\mathbf{1 9 9 2}$ & 53 & 69 & 7,46 \\
até 2.000 & 759 & 1.435 & 4,91 \\
de 2.001 a 5.000 & 1.033 & 3.101 & 3,90 \\
de 5.001 a 10.000 & 1.244 & 5.569 & 3,13 \\
de 10.001 a 20.000 & 1.120 & 10.028 & 2,61 \\
de 20.001 a 80.000 & 180 & 3.953 & 2,08 \\
de 80.001 a 200.000 & 102 & 9.423 & 1,57 \\
mais de 200.000 & 4.491 & 33.578 & 2,30 \\
Total & & & \\
1999 & 101 & 137 & 8,42 \\
até 2.000 & 1.170 & 2.133 & 5,17 \\
de 2.001 a 5.000 & 1.256 & 3.686 & 4,08 \\
de 5.001 a 10.000 & 1.322 & 6.376 & 3,37 \\
de 10.001 a 20.000 & 1.146 & 12.021 & 2,91 \\
de 20.001 a 80.000 & 185 & 4.928 & 2,22 \\
de 80.001 a 200.000 & 103 & 11.728 & 1,75 \\
mais de 200.000 & 5.283 & 41.009 & 2,52 \\
Total & & &
\end{tabular}

Fonte: Tabela criada a partir dos microdados da pesquisa AMS/1992 e 1999, IBGE.

${ }^{*}$ ) Apenas entre os municípios com pelo menos um estabelecimento de saúde no ano pesquisado. 
Figura 3

Variação do número de estabelecimentos sem internação segundo modalidade de prestação de serviços (SUS x NÃO SUS), Brasil - 1992 x 1999.

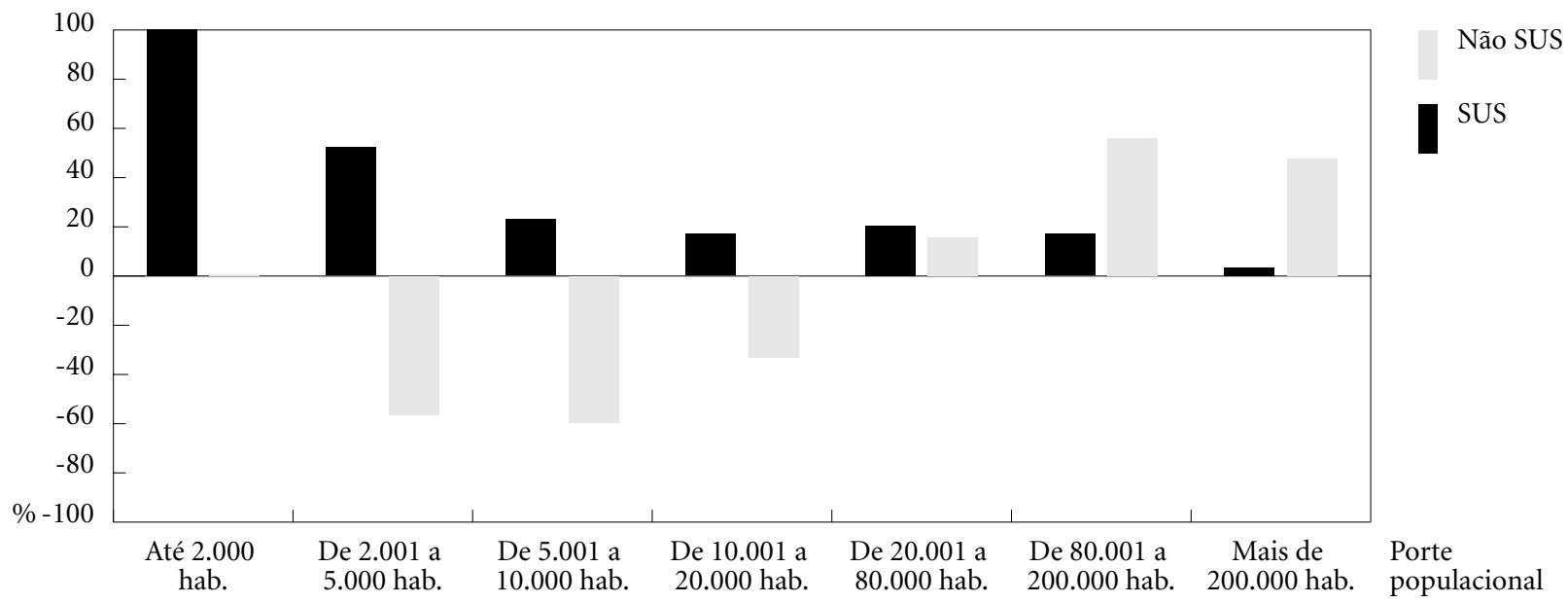

Fonte: Figura criada a partir dos microdados da pesquisa AMS/1992 e 1999, IBGE.

Tabela 5

Estabelecimentos de saúde sem internação por modalidade de prestação de serviços segundo porte do município - Brasil - 1992/1999 ( ${ }^{*}$.

\begin{tabular}{lcccc}
\hline $\begin{array}{l}\text { Porte populacional } \\
\text { (em habitantes) }\end{array}$ & Unidades SUS (a) & $\begin{array}{c}\text { Unidades } \\
\text { Não SUS }(\mathbf{b})\end{array}$ & Total (a)+(b) & $\begin{array}{c}\text { Freq. Relativa } \\
\text { SUS (a)/(a+b) }(\%)\end{array}$ \\
\hline $\mathbf{1 9 9 2}$ & & & & \\
até 2.000 & 68 & 1 & 69 & 98,55 \\
de 2.001 a 5.000 & 1.389 & 46 & 1.435 & 96,79 \\
de 5.001 a 10.000 & 2.951 & 150 & 3.101 & 95,16 \\
de 10.001 a 20.000 & 5.300 & 269 & 5.569 & 95,17 \\
de 20.001 a 80.000 & 9.131 & 897 & 10.028 & 91,06 \\
de 80.001 a 200.000 & 3.163 & 790 & 3.953 & 80,02 \\
mais de 200.000 & 4.951 & 4.472 & 9.423 & 52,54 \\
Total & 26.953 & 6.625 & 33.578 & 80,27 \\
1999 & & & & \\
até 2.000 & 136 & 1 & 137 & 99,27 \\
de 2.001 a 5.000 & 2.113 & 20 & 2.133 & 99,06 \\
de 5.001 a 10.000 & 3.625 & 61 & 3.686 & 98,35 \\
de 10.001 a 20.000 & 6.196 & 180 & 6.376 & 97,18 \\
de 20.001 a 80.000 & 10.984 & 1.037 & 12.021 & 91,37 \\
de 80.001 a 200.000 & 3.696 & 1.232 & 4.928 & 75,00 \\
mais de 200.000 & 5.118 & 6.610 & 11.728 & 43,64 \\
Total & 31.868 & 9.141 & 41.009 & 77,71 \\
\hline
\end{tabular}

Fonte: Tabela criada a partir dos microdados da pesquisa AMS/1992 e 1999, IBGE. 
Tabela 6

Número de empregos em unidades conveniadas com o Sistema Único de Saúde por regime de atendimento segundo grandes regiões - Brasil - 1992/1999.

\begin{tabular}{|c|c|c|c|c|c|}
\hline Grandes regiões & № de municípios $\left(^{*}\right.$ ) & $\begin{array}{c}\text { Empregos em } \\
\text { unidades SI }\end{array}$ & $\begin{array}{c}\text { Empregos em } \\
\text { unidades CI }\end{array}$ & $\begin{array}{c}\text { Empregos em } \\
\text { unidades DI }\end{array}$ & $\begin{array}{l}\text { Total de empregos } \\
\qquad(\mathrm{SI}+\mathrm{CI}+\mathrm{DI})\end{array}$ \\
\hline \multicolumn{6}{|l|}{1992} \\
\hline Norte & 298 & 13.826 & 21.970 & 1.299 & 37.095 \\
\hline Nordeste & 1.509 & 67.193 & 128.542 & 6.411 & 202.146 \\
\hline Sudeste & 1.432 & 132.977 & 285.519 & 11.905 & 430.401 \\
\hline Sul & 873 & 41.189 & 92.459 & 8.513 & 142.161 \\
\hline Centro-Oeste & 379 & 15.039 & 35.358 & 2.188 & 52.585 \\
\hline Brasil & 4.491 & 270.224 & 563.848 & 30.316 & 864.388 \\
\hline \multicolumn{6}{|l|}{1999} \\
\hline Norte & 419 & 28.365 & 32.906 & 1.251 & 62.522 \\
\hline Nordeste & 1.731 & 118.482 & 157.915 & 3.935 & 280.332 \\
\hline Sudeste & 1.602 & 174.171 & 333.535 & 11.556 & 519.262 \\
\hline Sul & 1.095 & 61.327 & 95.896 & 3.258 & 160.481 \\
\hline Centro-Oeste & 436 & 25.731 & 44.555 & 1.594 & 71.880 \\
\hline Brasil & 5.283 & 408.076 & 664.807 & 21.594 & 1.094 .477 \\
\hline
\end{tabular}

Fonte: Tabela criada a partir dos microdados da pesquisa AMS/1992 e 1999, IBGE.

Nota: Os empregos incluem profissionais de nível superior, técnico e auxiliar, não considerando os profissionais em funções administrativas.

${ }^{*}$ ) Apenas entre os municípios com pelo menos um estabelecimento de saúde no ano pesquisado.

Na classificação criada pelo IBGE, em 1999, SI - unidades sem internação, CI - unidades com internação,

DI - unidades de apoio à diagnose e terapia.

abaixo das médias nacionais no número de empregados na função saúde. Nesse estrato e no conjunto de grandes cidades, verificou-se uma queda nos empregos na saúde nos municípios situados em Sergipe, Alagoas, Bahia, Piauí, Paraíba. Alguns grupos de municípios com esse perfil nos estados de Mato Grosso do Sul, Espírito Santo, São Paulo, Rio de Janeiro e Santa Catarina também apresentaram esse comportamento.

- A região Sudeste apresenta uma variação no número de empregos bastante inferior ao observado para as demais regiões.

- Excetuando os casos dos municípios entre 80 a 200 mil, a região Nordeste teve um incremento no emprego municipal em saúde sempre superior ao resto do país.

- Na região Sul, os municípios que mais cresceram - acima da média nacional - quanto ao número de empregos municipais na saúde foram aqueles com até 2 mil habitantes em razão de terem dobrado em número de municípios entre 1992-1999.

No caso dos municípios muito pequenos, pode-se concluir que o crescimento incremental no número de empregos no setor saúde, em todos as regiões do país, está associado à criação de novas localidades entre 1992-1999.
Em relação ao conjunto dos municípios, o crescimento no emprego sofreu influência da demanda pela criação de estruturas administrativas e técnicas tanto para a implementação de programas de saúde como para a gestão organizacional dos processos de habilitação às definidos pela NOB 01/96. Em 1999 já era muito elevada a proporção de municípios brasileiros habilitados por essa Norma: 88,02\% em Gestão Plena da Assistência Básica e 9,39\% em Gestão Plena do Sistema Municipal.

Outro aspecto importante a ser ressaltado é o crescimento do número de profissionais de nível superior atuando no sistema básico e ambulatorial em todo o país (Tabela 8). Isso indica que os gestores locais não optaram por ampliar o número de hospitais e serviços de alto custo nos sistemas locais.

Os dados dessa tabela indicam, ainda assim, que o crescimento dos empregos SUS na área básica e ambulatorial entre 1992-1999 foi fortemente diferenciado, prevalecendo nas regiões um forte crescimento dos empregos de nível auxiliar, seguidos dos empregos de nível superior e pequena ampliação dos empregos de nível técnico.

A exceção é a região Sudeste, onde na maioria dos estados e estratos municipais houve um 
Tabela 7

Número de empregos em unidades conveniadas com o Sistema Único de Saúde por regime de atendimento segundo porte populacional - Brasil - 1992/1999.

\begin{tabular}{|c|c|c|c|c|c|}
\hline $\begin{array}{l}\text { Porte populacional } \\
\text { (em habitantes) }\end{array}$ & № de municípios $\left(^{*}\right)$ & $\begin{array}{c}\text { Empregos em } \\
\text { unidades SI }\end{array}$ & $\begin{array}{c}\text { Empregos em } \\
\text { unidades CI }\end{array}$ & $\begin{array}{c}\text { Empregos em } \\
\text { unidades DI }\end{array}$ & $\begin{array}{l}\text { Total de empregos } \\
\quad(\mathrm{SI}+\mathrm{CI}+\mathrm{DI})\end{array}$ \\
\hline \multicolumn{6}{|l|}{1992} \\
\hline até 2.000 & 53 & 422 & 126 & 2 & 550 \\
\hline de 2.001 a 5.000 & 759 & 7.534 & 3.872 & 49 & 11.455 \\
\hline de 5.001 a 10.000 & 1.033 & 13.926 & 13.182 & 320 & 27.428 \\
\hline de 10.001 a 20.000 & 1.244 & 26.040 & 31.174 & 872 & 58.086 \\
\hline de 20.001 a 80.000 & 1.120 & 60.787 & 95.088 & 6.987 & 162.862 \\
\hline de 80.001 a 200.000 & 180 & 34.283 & 70.705 & 5.037 & 110.025 \\
\hline mais de 200.000 & 102 & 127.232 & 349.701 & 17.049 & 493.982 \\
\hline Total & 4.491 & 270.224 & 563.848 & 30.316 & 864.388 \\
\hline \multicolumn{6}{|l|}{1999} \\
\hline até 2.000 & 101 & 1.125 & 149 & 1 & 1.275 \\
\hline de 2.001 a 5.000 & 1.170 & 18.069 & 5.567 & 58 & 23.694 \\
\hline de 5.001 a 10.000 & 1.256 & 30.680 & 17.219 & 162 & 48.061 \\
\hline de 10.001 a 20.000 & 1.322 & 54.940 & 38.778 & 446 & 94.164 \\
\hline de 20.001 a 80.000 & 1.146 & 113.245 & 114.446 & 3.019 & 230.710 \\
\hline de 80.001 a 200.000 & 185 & 52.853 & 79.234 & 3.859 & 135.946 \\
\hline mais de 200.000 & 103 & 137.164 & 409.414 & 14.049 & 560.627 \\
\hline Total & 5.283 & 408.076 & 664.807 & 21.594 & 1.094 .477 \\
\hline
\end{tabular}

Fonte: Tabela criada a partir dos microdados da pesquisa AMS/1992 e 1999, IBGE.

Nota: Os empregos incluem profissionais de nível superior, técnico e auxiliar, não considerando os profissionais em funções administrativas.

${ }^{*}$ ) Apenas entre os municípios com pelo menos um estabelecimento de saúde no ano pesquisado.

Na classificação criada pelo IBGE, em 1999, SI - unidades sem internação, CI - unidades com internação,

DI - unidades de apoio à diagnose e terapia.

Tabela 8

Variação do número total de empregos em unidades sem internação conveniadas ${ }^{*}$ ) com o Sistema Único de Saúde segundo grandes regiões - Brasil - 1992/1999 - (\%).

\begin{tabular}{lcccc}
\hline Grandes regiões & Nível superior & Nível técnico & Nível auxiliar & Total \\
\hline Norte & 90,16 & 36,65 & 128,90 & 105,16 \\
Nordeste & 45,36 & 40,17 & 105,58 & 76,33 \\
Sudeste & 30,25 & 90,62 & 23,98 & 30,98 \\
Sul & 42,36 & 55,38 & 56,62 & 48,89 \\
Centro-Oeste & 51,15 & 59,68 & 93,49 & 71,10 \\
Brasil & 38,29 & 64,64 & 63,25 & 51,01 \\
\hline
\end{tabular}

Fonte: Tabela criada a partir dos microdados da pesquisa AMS/1992 e 1999, IBGE.

${ }^{*}$ Apenas entre os municípios com pelo menos um estabelecimento de saúde no ano pesquisado.

expressivo incremento do emprego em atividades técnicas e profissionais em detrimento das atividades auxiliares, mais especificamente $o$ estado de São Paulo, que registra, por exemplo, um crescimento de $396 \%$ nos empregos técnicos entre 1992-1999 nas unidades do SUS. De modo geral, a região Sudeste apresenta uma variação abaixo da média nacional do número de empregos em todas as categorias.
O crescimento do emprego em funções auxiliares foi fortemente sustentado pelos pequenos municípios em todos os estratos populacionais municipais, independente do estado ou região. Apenas os municípios do estado de Minas Gerais não obedeceram a esse padrão.

Os dados da tabela 9 revelam que os municípios brasileiros de pequeno a médio porte (até 80 mil habitantes) responderam de modo 
muito responsável aos incentivos da descentralização. O ano de 1999 já apresenta algumas características de mudança na composição da força de trabalho em saúde por uma combinação multifuncional em razão do forte crescimento na contratação de técnicos e auxiliares na composição do emprego setorial, com a redução da participação dos empregos médicos em relação ao total de empregos de nível superior. Observa-se ainda que o crescimento na composição multifuncional dos empregos é também sustentado pelo incremento, mesmo que em ritmo mais lento, do emprego de profissionais de nível superior (não médico) na rede ambulatorial e básica do SUS. Essa parece ser uma solução adequada para a ampliação de cobertura no Brasil em razão do elevado déficit de profissionais médicos na estrutura do Sistema Único de Saúde constatada para todo o país, com exceção das capitais e alguns núcleos urbanos prósperos, como veremos a seguir.

O Ministério da Saúde, com a portaria de número 35, de 1999, ao conceituar os tipos de unidade de saúde existentes no setor público brasileiro, estabelece que, dentre as dezenas de especialidades médicas reconhecidas pelo Conselho Federal de Medicina (CFM), quatro são consideradas "básicas": medicina interna (clínica médica), pediatria, ginecologia e obstetrícia. Essas seriam as áreas típicas de atuação dos profissionais que desenvolvem ações de atenção básica.

Diversos estudos (Carvalho, 1966; Médici, 1987; Machado et al., 1995; Pinto, 1999) demonstram que a relação de médicos por 1.000 habitantes é elevada nas capitais do Brasil e em algumas cidades do interior, principalmente naquelas onde há oferta de programas de residência médica.

Se desenvolvermos uma análise mais detalhada a esse respeito poderemos notar que, na verdade, a concentração de médicos está diretamente correlacionada ao porte populacional, ou seja, quanto maior o tamanho de uma cidade maior a presença do profissional. Por exemplo, em 2000, os 107 municípios brasileiros com mais de 200.000 habitantes possuíam cerca de 70,2 milhões de pessoas e 80.000 médicos, o que daria uma relação de 1,14 médicos por 1.000 habitantes. Já para os 2.642 municípios com

\section{Tabela 9}

Número total de empregos de nível superior em unidades sem internação conveniadas com o Sistema Único de Saúde segundo porte populacional - Brasil - 1992/1999.

\begin{tabular}{|c|c|c|c|c|c|}
\hline $\begin{array}{l}\text { Porte populacional } \\
\text { (em habitantes) }\end{array}$ & № de municípios ${ }^{*}$ ) & $\begin{array}{l}\text { Empregos } \\
\text { médicos (a) }\end{array}$ & $\begin{array}{l}\text { Outros empregos } \\
\text { nível superior (b) }\end{array}$ & $\begin{array}{l}\text { Total de empregos } \\
\text { nível superior (c) }\end{array}$ & $\begin{array}{l}\text { Participação dos } \\
\text { empregos médicos } \\
\text { (a) } /(\text { c) }(\%)\end{array}$ \\
\hline \multicolumn{6}{|l|}{1992} \\
\hline até 2.000 & 53 & 96 & 68 & 164 & 58,54 \\
\hline de 2.001 a 5.000 & 759 & 1.690 & 1.249 & 2.939 & 57,50 \\
\hline de 5.001 a 10.000 & 1.033 & 3.138 & 2.210 & 5.348 & 58,68 \\
\hline de 10.001 a 20.000 & 1.244 & 6.267 & 4.231 & 10.498 & 59,70 \\
\hline de 20.001 a 80.000 & 1.120 & 16.876 & 10.223 & 27.099 & 62,28 \\
\hline de 80.001 a 200.000 & 180 & 11.788 & 6.517 & 18.305 & 64,40 \\
\hline mais de 200.000 & 102 & 41.833 & 27.223 & 69.056 & 60,58 \\
\hline Total & 4.491 & 81.688 & 51.721 & 133.409 & 61,23 \\
\hline \multicolumn{6}{|l|}{1999} \\
\hline até 2.000 & 101 & 233 & 255 & 488 & 47,75 \\
\hline de 2.001 a 5.000 & 1.170 & 3.656 & 3.705 & 7.361 & 49,67 \\
\hline de 5.001 a 10.000 & 1.256 & 6.508 & 5.630 & 12.138 & 53,62 \\
\hline de 10.001 a 20.000 & 1.322 & 11.506 & 9.593 & 21.099 & 54,53 \\
\hline de 20.001 a 80.000 & 1.146 & 26.068 & 19.324 & 45.392 & 57,43 \\
\hline de 80.001 a 200.000 & 185 & 16.508 & 10.870 & 27.378 & 60,30 \\
\hline mais de 200.000 & 103 & 40.125 & 30.505 & 70.630 & 56,81 \\
\hline Total & 5.283 & 104.604 & 79.882 & 184.486 & 56,70 \\
\hline
\end{tabular}

Fonte: Tabela criada a partir dos microdados da pesquisa AMS/1992 e 1999, IBGE.

${ }^{*}$ ) Apenas entre os municípios com pelo menos um estabelecimento de saúde no ano pesquisado. 
menos de 10.000 habitantes, que representam uma população total de 13,8 milhões de pessoas, apenas 7.500 médicos atuavam nesses locais, no mesmo período, ou seja, 0,55 médicos por 1.000 habitantes.

A despeito da mudança na ampliação da rede básica ao longo da década, a oferta de profissionais médicos com atuação na rede básica ainda é baixa no país.

Se considerada a proposta do Ministério da Saúde que preconiza uma relação mínima de 0,8 médico/1.000 habitantes para médicos generalistas, entendendo-se nesse caso como "generalistas" aqueles que atuam nas quatro especialidades básicas da medicina (Ministério da Saúde, 2002), a situação na oferta de médicos na atenção básica é precária, não importando a natureza do município. Nas localidades de menos de 10.000 habitantes, a relação média é de 0,46 médicos/1.000 habitantes; nas cidades de mais de 200.000 habitantes, a relação é de 0,47 médicos/1.000 habitantes.

Para efeito de conclusão, é possível indicar que a década de 1990 não permitiu encaminhamento de soluções abrangentes para as políticas sociais no Brasil em razão dos pressupostos aceitos para a integração da economia brasileira no cenário da integração do país ao mercado financeiro internacional. Esses pressupostos provocaram um real constrangimento ao financiamento social pela diminuição do grau de liberdade para as decisões orientadas para os interesses domésticos.

A agenda social esteve condicionada a duas soluções macropolíticas não triviais:

1) a garantia das condições de estabilidade macroeconômica, para realizar a reforma do Estado e retomar o crescimento econômico - "sob as novas condições de abertura da economia e elevada competição" (Presidência da República: 1996);

2) a concentração do esforço e da atenção nos serviços básicos sociais de vocação universal: educação, saúde, previdência social, habitação e saneamento básico, trabalho e assistência social.
Os dados deste trabalho mostram que o setor saúde teve relativo sucesso na iniciativa da descentralização, com a ampliação da oferta de atenção básica ambulatorial e o impacto redistributivo nas transferências federais. Esses dados valem como exercício de análise para o sucesso de um programa específico, como o PAB, embora seja difícil avaliar os seus efeitos mais abrangentes sobre as dimensões de eqüidade do sistema de saúde brasileiro.

Para essa análise mais abrangente é ainda fundamental considerar: 1) as mudanças no padrão de oferta do segmento de prestadores de serviços de saúde para os planos e seguros de saúde vis-à-vis à oferta SUS; 2) a disponibilidade de serviços SUS ambulatoriais, hospitalares e de exames complementares nas periferias das grandes e médias cidades brasileiras; 3 ) as características das despesas com a função atenção à saúde dos estratos de renda familiar mais baixos das regiões metropolitanas. Certamente esses dados podem oferecer um conjunto adicional de evidências para uma avaliação mais apropriada do sistema de saúde brasileiro.

Os dados de variação da oferta ambulatorial básica no SUS para as pequenas cidades do país por força do PAB mostram que um caminho foi parcialmente percorrido. Esse percurso foi favorecido, sem dúvida, pelas condições específicas da boa governança setorial do SUS. Porém, cabe fazer as devidas correções e começar a construção de uma nova agenda para a política pública setorial. Um bom começo será o abandono completo das estratégias de ampliação de cobertura e universalização pelo uso recorrente da noção de "serviços básicos de vocação universal”. Esse é o caminho para a completa pulverização e desmantelamento de uma institucionalidade da cidadania sanitária plena. Tendo em vista a crescente mudança no complexo industrial da saúde, que determina a grande diferenciação na oferta de serviços de saúde para os segmentos de maior renda e inseridos no mercado formal de trabalho, cabe retomar o tema da desigualdade visando a uma nova agenda para o Sistema Único de Saúde. 


\section{Referências bibliográficas}

Barros Silva PL \& Costa NR 2000. A avaliação de programas públicos: reflexões sobre a experiência brasileira. Projeto Avaliação de Políticas Públicas na América do Sul-Relatório Parcial. IPEA, Brasília.

Berman P 2000. Organization of ambulatory care provision: a critical determinant of health system performance in developing countries. Bulletin of The WHO 78(6):791-802

Bossert T 1998. Analyzing the decentralization of health hystems in developing countries. Decision Space, Innovation and Performance. Social Science and Medicine 47(10):1.513-1.527.

Carvalho AVW 1966. Estatísticas médico-sanitárias: médicos. (Prefácio). Ministério da Saúde/Serviço de Estatística, Rio de Janeiro.

Costa et al. 2002. Custo e avaliação de impacto da implantação da parte fixa do Piso de Atenção Básica (PAB). Relatório final de pesquisa. Escola Nacional de Saúde Pública/Fiocruz/Reforsus, Rio de Janeiro.

Donabedian A 1984. La calidad de la atención médicadefinición e métodos de evaluación. La Prensa Médica Mexicana, S.A., Cidade do México.

Machado MH et al., 1995. Especialidades médicas no Brasil. Dados, Radis (17):2-31.
Médici AC 1987. Estrutura e dinâmica da força de trabalho médico no Brasil na década de setenta. In Médici AC (org.). Texto de apoio: planejamento I, recursos humanos em saúde. PEC/ENSP, Rio de Janeiro.

Ministério da Saúde 2000. Departamento de Informática do SUS (DATASUS). Brasília, 6/6/2002. Disponível em $<$ www.datasus.gov.br> Acessado em 3 de junho de 2000.

Ministério da Saúde 2002. Portaria 1.101. Secretaria de Assistência à Saúde (SAS)/Ministério da Saúde, Brasília. 12 de junho de 2002, p.10.

Pinto LF 1999. Médicos e migração: a residência em foco. Dissertação de mestrado. Escola Nacional de Saúde Pública/Fiocruz, Rio de Janeiro.

Presidência da República 1996. Uma estratégia de desenvolvimento social. Governo Federal, Brasília.

Vianna SM \& Piola SF 1999. Descentralização e gestão do gasto público com saúde no Brasil. Texto produzido para o XI Seminário Regional de Política Fiscal. Cepal/ Ipea.

World Bank 1998. Brazil - fiscal adjustment and social spending. The case of education and health in four Brazilian states. Washington, Estados Unidos.

Artigo apresentado em 10/9/2002

Aprovado em 17/10/2002

Versão final apresentada em 5/11/2002 